\title{
Concepções Parentais sobre Intencionalidade Comunicativa em Bebês aos 3 e 6 Meses
}

\author{
Laísy de Lima Nunes - Universidade Federal da Paraíba, João Pessoa, Brasil \\ Fabiola de Sousa Braz. Aquino - Universidade Federal da Paraíba, João Pessoa, Brasil \\ Nádia Maria Ribeiro Salomão - Universidade Federal da Paraíba, João Pessoa, Brasil
}

\begin{abstract}
Resumo
O presente estudo objetivou conhecer e analisar as concepções parentais acerca da intencionalidade comunicativa de bebês aos 3 e 6 meses do primeiro ano de vida. Foi utilizado um delineamento longitudinal, com a participação de 20 mães e de 20 pais, entrevistados em duas etapas. As entrevistas foram transcritas de forma literal e, em seguida, analisadas qualitativamente. Foram identificadas mais semelhanças do que diferenças entre os discursos maternos e paternos. Constatou-se que os relatos parentais apresentaram concepções que comportamentos infantis específicos podem ser indícios da habilidade de comunicação intencional. Especialmente na segunda etapa, quando os bebês tinham 6 meses de idade, os pais referiram comportamentos infantis que seriam exibidos para expressar vontades e indicar intenção. O conhecimento dessas concepções é importante para a compreensão das relações iniciais estabelecidas entre pais e seus filhos.

Palavras-chave: cognição social, intencionalidade, desenvolvimento infantil, relações pais-criança
\end{abstract}

Parental Conceptions of Communicative Intentionality in Infants at 3 and 6 Months

\begin{abstract}
This study aimed to identify and analyze parental conceptions of the communicative intent of infants at 3 and 6 months in the first year of life. A longitudinal design was used, including 20 mothers and 20 fathers who were interviewed in two stages. The interviews were literally transcribed and then qualitatively analyzed. It was identified more similarities than differences between maternal and paternal speeches. It was found that parental reports presented conceptions that specific child behavior may be evidence of intentional communication skills. Especially in the second stage, when infants were 6 months old, parents mentioned child behavior that seemed to express wishes and indicate intention. Knowledge of these concepts is important for understanding the early relations between parents and their children.

Keywords: social cognition; intentionality; infant development; parent-child relationships.
\end{abstract}

\section{Concepciones de los Padres de la Intencionalidad Comunicativa en los Bebés a los 3 y 6 Meses}

\begin{abstract}
Resumen
Este estudio tuvo como objetivo conocer y analizar las concepciones de los padres sobre la intención comunicativa de los bebés a los 3 y 6 meses en su primer año de vida. Se utilizó un delineamiento longitudinal, y participaron 20 madres y 20 padres entrevistados en dos etapas. Las entrevistas fueron transcriptas literalmente y analizadas cualitativamente. Fueron identificadas más semejanzas que diferencias entre los discursos maternos y paternos. Se constató que los informes de los padres presentan concepciones sobre el hecho de que, comportamientos infantiles específicos, pueden ser indicios de la habilidad de comunicación intencional. Especialmente en la segunda etapa, cuando los bebés tenían 6 meses de edad, los padres indicaron que comportamientos infantiles fueron exibidos para expresar deseos e indicar la intención. El conocimiento de esas concepciones es importante para la comprensión de las relaciones iniciales estabelecidas entre padres y sus hijos.

Palabras-clave: cognición social; intención; desarrollo infantil; relaciones padres-niños.
\end{abstract}

\section{Introdução}

O interesse pelo estudo da intencionalidade comunicativa infantil tornou-se evidente a partir da década de 1970, como parte importante de pesquisas sobre a ontogênese humana e a evolução da comunicação pré -linguística para a comunicação verbal (Braz Aquino \& Salomão, 2010). Ao realizar um levantamento sobre o tema, Sanchez (1991) cita como marco o trabalho realizado por Susan Sugarman, em 1973. Este representa o primeiro estudo empírico acerca da intenção comunicativa em bebês, no qual a comunicação intencional foi identificada como a coordenação ou combinação, por parte da criança, das ações direcionadas a um objeto e a uma pessoa.

A partir da retrospectiva feita nesse campo, Sanchez (1991) afirma que a Psicologia Evolutiva e a Psicolinguística, com o enfoque pragmático, foram as principais áreas que desenvolveram estudos sobre essa temática. Além dessas, atualmente, outras áreas de conhecimento buscam compreender o desenvolvimento da habilidade de comunicação intencional. Entre as principais, destacam-se as que estão fundamentadas em teorias que seguem pressupostos interacionistas (Rivero, 2003), sociopragmáticos (Carpenter, 2011, Tomasello, 2003), sociocognitivos (Rochat, 2015; Striano \& Reid, 2006), 
neurocognitivos (Dunbar, 2013; Trevarthen \& Delafield-Butt, 2013) e na teoria da mente (Frye, 2014).

Essas diferentes teorias discutem e buscam evidências sobre os fatores envolvidos no desenvolvimento da intencionalidade comunicativa e o período no qual essa habilidade emerge. Especificamente sobre as discussões relativas à idade, Striano e Rochat (1999) afirmam que indícios de comportamentos comunicativos intencionais podem ser verificados em bebês nos meses iniciais após o nascimento. Tomasello (2003), por sua vez, apesar de considerar os avanços sociocomunicativos dos bebês desde o nascimento, defende que a emergência da habilidade de comunicação intencional ocorre no último trimestre do primeiro ano de vida do bebê.

Segundo essa última linha teórica (Carpenter, 2011; Tomasello, 2003; Grosse, Behne, Carpenter, \& Tomasello, 2010), a habilidade de comunicação intencional emerge entre os 9 e 12 meses de idade e inclui: a habilidade de compartilhar atenção com outras pessoas para objetos e eventos de interesse mútuo; a habilidade de acompanhar a atenção e gestos dos outros para objetos que não estão na interação imediata; chamar a atenção dos outros para objetos por meio do apontar, mostrar e usar outros gestos não linguísticos; e a habilidade de aprender culturalmente as ações intencionais dos outros, incluindo seus atos comunicativos.

A partir do último trimestre do primeiro ano de vida, os bebês começam a usar os adultos como pontos de referência social e agir com os objetos do mesmo modo que os adultos agem (Tomasello, 2003). As interações face a face entre as díades mãe-bebê passam a ser triádicas, envolvendo o bebê, o adulto e um objeto ou evento externo. Nesse tipo de interação, o bebê é capaz de compartilhar a atenção com o parceiro e apresenta comportamentos intencionais que passam a integrar o repertório de ações infantis, como o apontar (Carpenter, 2011; Grosse et al., 2010). Essas capacidades evidenciam o caráter intencional adquirido a partir da chamada "revolução dos nove meses" (Tomasello, 2003).

Baseados em outra perspectiva teórica, Striano, Rochat e colaboradores (Rochat, 2009, 2015; Striano \& Reid, 2006; Striano \& Rochat, 1999; Striano \& Stahl, 2005) afirmam que, aos 2 meses, os bebês têm diversas habilidades comunicativas, sendo capazes, por exemplo, de usar movimentos para sinalizar um objeto desejado, como movimentar o corpo, levantar braços ou mãos. Esses autores fazem referência à revolução dos 2 meses, na qual as habilidades sociocognitivas continuam a se desenvolver e aparecem os primeiros sinais de comportamentos intencionais.

Nessa fase, os bebês apresentam um foco visual melhorado e a mudança de sua atenção visual pode ser constatada pelo movimento dos olhos (Rochat, 2015). De acordo com a perspectiva apresentada por esses teóricos, o bebê pode demonstrar seu interesse olhando na direção do que chama sua atenção ou rejeitar algo olhando para outro lado. Esses movimentos oculares, quando sistemáticos em direção às mãos e, principalmente, aos olhos e à boca do parceiro social, são importantes sinais de interação diádica e indicam uma forma de compreensão mútua. Em outras palavras, aos 2 meses, os bebês começam a olhar fixamente para os olhos e a boca da outra pessoa e demonstram evidências de sensibilidade a contingências interpessoais (Rochat, 2007, 2015; Striano \& Rochat, 1999).

Ainda no segundo mês, os bebês mostram sinais claros de diferenciação entre si e o mundo, e são capazes de explorar e contemplar as consequências de suas ações no meio. Nesse período, eles apresentam um senso de experiência compartilhada e, nas interações face a face, criam intercâmbio em sincronia e alternância, compartilhando emoções (Rochat, 2007, 2009). Em torno dos 3 meses de idade, os bebês são capazes de acompanhar e responder a diversas ações dos parceiros sociais. Ao longo do desenvolvimento, esses comportamentos infantis vão se aprimorando progressivamente e possibilitam novas formas de interação.

A partir dos 6 meses, os jogos sociais são evidenciados e permitem que os bebês sejam mais responsivos. Nesse período, eles desenvolvem um conjunto de capacidades para avaliar a direção do olhar de outra pessoa e acompanhá-lo. Esse desenvolvimento torna o bebê apto a acompanhar a linha do olhar do adulto além do contato olho a olho, o que acarreta contribuições significativas para a comunicação, aumentando a sintonia infantil com as ações dos seus cuidadores. Tais habilidades aumentam de forma constante nos meses seguintes e precedem o ato de apontar, além de serem necessárias para engajamentos de atenção conjunta posteriormente (Papalia \& Feldman, 2013).

O conjunto de comportamentos comunicativos e interativos citado é essencial ao desenvolvimento da cognição social infantil (Rochat, 2015; Striano \& Rochat, 1999). Esse conceito é entendido como um tipo diferente de cognição, exclusivamente humana, que possibilita ao ser humano, ainda muito novo, entender o outro como agente intencional, com estados mentais 
distintos (Carpenter, 2011; Tomasello, 2003). De acordo com Striano e Reid (2006), a cognição social infantil refere-se à

\begin{abstract}
habilidade para compreender outras pessoas (...) e inclui todas as habilidades perceptivas básicas que nos habilitam a discriminar pessoas de objetos e o complexo interjogo de pistas sociais como o contato visual, movimentos do corpo, tom de voz e expressões faciais auxiliando na interpretação dos comportamentos dos outros e na capacidade e funcionamento da comunicação simbólica (p. 471).
\end{abstract}

Estudos nessa área (Legerstee, 2013; Mendes \& Pessôa, 2013) destacam a relação entre a cognição social, a intencionalidade, os comportamentos sensório-motores e a afetividade. Segundo Legerstee (2013), para que o bebê compreenda o estado mental do outro, é necessário que ele seja capaz de sentir o que o outro sente e de representar o que o outro representa. As expressões emocionais do bebê, assim como a capacidade de reconhecer emoções, favorecem o desenvolvimento da habilidade de comunicação intencional e de atenção (Legerstee, 2013; Mendes \& Pessôa, 2013). Enquanto as contingências e imitações chamam a atenção do bebê para os outros sociais, a comunicação afetiva aparece para estabelecer as bases da consciência social infantil e subsequentes interações sociais.

Nesse sentido, reforça-se a importância das primeiras interações sociais do bebê, especialmente com os pais que, de forma geral, são os primeiros cuidadores. Pontua-se que as interações estabelecidas serão influenciadas, direta ou indiretamente, pelas concepções que esses adultos têm sobre o desenvolvimento infantil. A maneira como os pais compreendem o desenvolvimento de seus filhos pode, implícita ou explicitamente, influenciar o ambiente que eles promovem para os bebês, bem como os recursos utilizados e algumas especificidades da interação que ajudam a promover o desenvolvimento saudável (Feldman \& Reznick, 1996; Nunes \& Braz Aquino, 2014).

Destaca-se que as crenças sobre a habilidade mental infantil podem interferir nas estratégias parentais utilizadas para detectar e responder aos estados e objetivos dos bebês. Especificamente sobre o estudo das concepções acerca da habilidade infantil de comunicação intencional, Feldman e Reznick (1996), em um estudo realizado com mães de bebês aos 4 e aos 8 meses, verificaram que as participantes diferiram muito entre si. Enquanto algumas mães atribuíram intencionalidade aos atos infantis de forma constante, outras hesitaram em fazê-lo e, por vezes, deixaram alguns comportamentos passarem despercebidos. As diferenças nessas formas de percepções sobre a intencionalidade e o modo de comportamento infantil podem ter consequências importantes ao longo do desenvolvimento da criança (Burchinal, Skinner, \& Reznick, 2010).

Feldman e Reznick (1996) também constataram que alguns bebês podem ser percebidos como menos intencionais e apresentar relativamente menos sinais claros de intencionalidade. Relacionado a isso, Burchinal, Skinner e Reznick (2010) advertem que mães que subestimam a habilidade de comunicação intencional infantil podem não estimular apropriadamente seus filhos, e mães que superestimam essa capacidade podem ter uma inclinação a punir fisicamente seus bebês, caso percebam os comportamentos infantis considerados inadequados como sendo dotados de intenção.

Assim como os trabalhos de Feldman e Reznick (1996) e de Burchinal et al. (2010), a maioria dos estudos nessa área apresenta apenas as concepções maternas acerca da habilidade de comunicação intencional infantil, todavia alguns deles apontam a importância de que novas pesquisas sejam realizadas também com os pais (Bueno \& Vieira, 2014; Seabra \& Seidl de Moura, 2011).

Anteriormente, a ideia de paternidade vinculava-se a de um homem que se ausentava de casa para trabalhar e obter recursos financeiros. Nesse período, a mãe era representada como o principal agente no desenvolvimento da personalidade da criança. No entanto, devido às mudanças sociais ocorridas, principalmente, após a década de 1960, como a emancipação da mulher, estabeleceram-se novas relações entre homens e mulheres, levando ao aparecimento de novos padrões familiares e à redistribuição de papéis (Seabra \& Seidl de Moura, 2011).

Surge, então, um novo ideal de coparentalidade, no qual ambos os pais partilham responsabilidades e tarefas nos domínios financeiro, doméstico e nos cuidados das crianças de um modo mais igualitário, resultando na diluição da divisão baseada unicamente no gênero (Dessen \& Oliveira, 2013; Seabra \& Seidl de Moura, 2011). Considera-se, entretanto, por que a construção desse ideal de coparentalidade será influenciada por característica de cada família, como os níveis socioeconômico e educacional. De acordo com Dessen e Oliveira (2013) e Vieira et al. (2014), o aumento da participação do pai nas atividades diárias relacionadas com as crianças parece fortalecer uma relação de base segura com o progenitor, importante para o desenvolvimento 
psíquico e emocional da criança. A experiência paterna nos cuidados poderá facilitar o modo como os pais interpretam e respondem aos sinais infantis.

Diante do exposto, destaca-se o papel do pai e da mãe no desenvolvimento infantil e objetiva-se, neste estudo, conhecer e analisar as concepções parentais acerca da intencionalidade comunicativa de bebês em dois períodos do desenvolvimento. Para isso, foram escolhidas as idades de três e seis meses do primeiro ano de vida dos bebês por entender a importância de acompanhar o desenvolvimento inicial infantil e as transformações que ocorrem nesse período, tanto nos comportamentos dos próprios bebês como nas concepções parentais (Castoldi, Gonçalves, \& Lopes, 2014; Souza, Machado, Nunes, \& Braz Aquino, 2014).

\section{Método}

\section{Delineamento}

Foi utilizado o delineamento longitudinal. A partir da compreensão do desenvolvimento infantil como um processo, esse tipo de delineamento permitiu conhecer, por meio dos relatos parentais, as possíveis modificações nos comportamentos infantis que podem fornecer pistas sobre a emergência da habilidade de comunicação intencional nos meses iniciais.

\section{Participantes}

Foram entrevistados 20 casais em dois períodos distintos ao longo do primeiro semestre de vida do bebê, quais sejam, três e seis meses. Catorze casais participantes tinham apenas um filho, e seis casais tinham dois filhos, sendo que a entrevista foi referente ao filho mais novo. Todos os bebês nasceram a termo e apresentavam desenvolvimento típico. Os participantes eram casados ou conviviam maritalmente. A idade das mães variou entre 20 e 36 anos, com média de 28,9 (DP $=4,91)$. A idade dos pais variou entre 23 e 35 anos, com média de 30,25 (DP = 4,12). Sobre o nível de escolaridade, entre as mães: 13 com o ensino superior; cinco com o ensino superior incompleto e duas com o ensino médio completo. Entre os pais: 12 com o ensino superior; seis com o ensino superior incompleto; e dois com o ensino médio completo.

Sobre as atividades laborais, na $1^{\text {a }}$ etapa da pesquisa, 13 mães estavam de licença-maternidade, quatro mães estudavam/trabalhavam fora do ambiente domiciliar entre quatro e seis horas por dia, e três mães haviam parado de trabalhar para se dedicarem aos cuidados dos bebês. Nessa etapa, 18 pais trabalhavam fora do ambiente doméstico, a maioria por oito horas diárias, e dois estavam de férias. $\mathrm{Na} 2^{\mathrm{a}}$ etapa, 10 mães trabalhavam/estudavam fora, a maioria por menos de seis horas diárias; quatro mães continuavam de licença-maternidade (por terem tirado a licença e as férias); e seis mães não estavam trabalhando fora de casa. Todos os pais estavam trabalhando, a maioria oito horas por dia.

\section{Instrumento}

Foram utilizados um questionário sociodemográfico e uma entrevista semiestruturada, que buscava conhecer as concepções parentais sobre a habilidade de comunicação intencional dos bebês. Para a formulação da entrevista, foi utilizada parte do roteiro adaptado por Nunes e Braz Aquino (2014) a partir do Infant Intentionality Questionnaire (IIQ) (Feldman \& Reznick, 1996). No processo de adaptação desse instrumento, ele teve sua forma original, uma escala de cinco pontos, modificada para o formato de entrevista semiestruturada, considerando-se que o tipo de estrutura inicial reduzia as possibilidades de resposta dos participantes e limitava uma compreensão mais aprofundada sobre suas concepções acerca da comunicação intencional infantil. Além disso, o IIQ passou por um processo de tradução e pela análise de juízes peritos na área do desenvolvimento infantil, que avaliaram a adequabilidade das questões, alterando o uso de alguns termos e a formulação de questões. Para registrar os relatos parentais, foi utilizado um gravador de áudio.

\section{Procedimento de Coleta de Dados}

Inicialmente, o projeto foi submetido ao Comitê de Ética em Pesquisa. Após a aprovação, teve início a coleta de dados, respeitando todos os procedimentos éticos estabelecidos para pesquisa com seres humanos, de acordo com a Resolução 466\12 da CONEP \MS. A amostra foi definida aleatoriamente por indicação, e os dados foram coletados nas próprias residências dos participantes ou em outros locais escolhidos pelos casais. Cada participante foi entrevistado separadamente nas duas etapas da coleta. O tempo médio de duração das entrevistas foi de aproximadamente 11 minutos.

\section{Procedimento de Análise dos Dados}

Primeiramente, foi realizado um levantamento dos dados sociodemográficos. No tocante às entrevistas, elas foram transcritas de forma literal, em seguida, foi realizada a leitura flutuante e o levantamento das 
respostas dos participantes, sendo feita uma análise de conteúdo, que seguiu as diretrizes gerais de categorização propostas por Bardin (1977/2002).

A análise das entrevistas permitiu identificar as concepções parentais sobre a intencionalidade comunicativa infantil e organizá-las em quatro seções, de acordo com os objetivos das questões e estrutura do instrumento utilizado. As seções são: 1) Concepções parentais acerca da percepção do bebê sobre seus próprios estados; 2) Concepções parentais acerca da percepção do bebê de comunicar e satisfazer suas próprias necessidades; 3) Concepções parentais acerca da percepção do bebê sobre os estados dos outros; e 4) Concepções parentais acerca da percepção dos bebês sobre a eficácia dos seus comportamentos nas interações com outros.

\section{Resultados}

As concepções parentais sobre a intencionalidade comunicativa infantil serão apresentadas de acordo com as seções elencadas durante a análise dos dados. Além disso, serão utilizados os termos " 1 a etapa" e " 2 a etapa" em referência às idades dos bebês quando os pais foram entrevistados, três e seis meses de vida, respectivamente.

\section{Concepcôes Parentais acerca da Percepção do Bebê sobre seus Pró- prios Estados}

Inicialmente, foi perguntado aos pais sobre as emoções (felicidade, amor, medo, surpresa, raiva, tristeza e culpa) que eles achavam que seus bebês podiam sentir e como eles as expressavam. Questionados sobre a capacidade infantil de sentir felicidade, todos os participantes, em ambas as etapas da pesquisa, responderam positivamente. De modo mais específico, 10 mães e 15 pais na $1^{a}$ etapa e 19 mães e 20 pais na $2^{a}$ etapa mencionaram o sorriso como principal comportamento expressivo de felicidade, como demonstrado no exemplo: "É quando ele tá contente, tá feliz, é rindo, né, ele sorri bastante." (M4, 3 meses). Em seguida foi mencionada a agitação corporal do bebê, referida, aos 3 meses por uma mãe e um pai, e aos 6 meses por cinco mães e três pais. O recorte de fala abaixo ilustra os relatos parentais sobre esse comportamento: "Um movimento de corpo, ela se mexe toda, ela fica alegre, ela praticamente dança." (P18, 6 meses). Foram referidas também, em menor frequência, as vocalizações e bater palmas.

A quase totalidade dos pais e mães participantes, nas duas etapas da pesquisa, mencionou perceber em seus bebês expressões de amor. Apesar das afirmações, os relatos evidenciaram diferenças na visão dos pais sobre os comportamentos utilizados pelos bebês para expressar tal sentimento em função do período de desenvolvimento infantil. $\mathrm{Na} 1^{\mathrm{a}}$ etapa, o sorriso (sete mães e quatro pais) e o olhar (uma mãe e um pai) foram os comportamentos principais por meio dos quais os pais percebiam expressões amorosas dos seus filhos. Os relatos também remeteram a expressões de carinho (duas mães); "querer ir para o braço" (uma mãe e um pai); e gritar (uma mãe).

$\mathrm{Na} 2^{\mathrm{a}}$ etapa, conforme as falas parentais, os bebês expressavam amor de forma mais ativa, por meio de expressões de carinho, como abraçar e beijar, mencionado por 12 mães e 10 pais, como exposto no exemplo: "Ela abraça, ela dá beijo, ela pega assim ó, aí vem dá o beijo babado, abraça." (M15). Também foram mencionados: o sorriso, por quatro mães e cinco pais; "querer ir para o braço", por duas mães e um pai; e o olhar, referido por três mães. Ainda nessa questão, uma mãe e dois pais de bebês aos 6 meses responderam que não sabem se seus filhos podem sentir amor: "Eu não sei se é amor. Eu não sei definir se é amor ou dependência, né? Tem aquela coisa que ele sabe que eu sou o conforto dele maior, né. Então, quando eu chego, ele se tranquiliza mais, se ele tiver chorando, mas eu não sei se é amor não." (M5).

O terceiro sentimento que a maioria dos pais relatou que seus bebês podem sentir foi medo. A resposta afirmativa sobre esse sentimento foi dada por 19 mães e 17 pais na $1^{\mathrm{a}}$ etapa, e por 16 mães e 17 pais na $2^{\mathrm{a}}$ etapa. Em ambas as etapas, o principal comportamento que os pais indicaram como sendo utilizados para expressar medo foi o choro, referido por 13 mães e cinco pais, na primeira, e por sete mães e sete pais na segunda. Outro comportamento referido foi "faz cara de espanto", relatado por duas mães e dois pais, e uma mãe e um pai, aos 3 e 6 meses dos bebês respectivamente. "Segurar nos pais" também foi indicado por uma mãe e um pai, na $1^{\mathrm{a}}$ etapa, e duas mães e um pai, na $2^{\mathrm{a}}$ etapa.

Perguntados se seus filhos poderiam sentir surpresa, a maioria dos pais nas duas etapas respondeu afirmativamente. A principal forma de expressá-la foi mencionada como "cara de surpresa", referida por três mães e seis pais quando os bebês estavam com 3 meses, e 12 mães e 12 pais aos 6 meses, tipicamente marcada pelos olhos arregalados e a boca aberta, como ilustrado no exemplo: "Ele abre a boca, [...] já abre o olho, abre a boca. Até escutar o barulhinho, ele fica (mãe faz expressão de surpresa)." (M12, 3 meses). Outro 
comportamento apontado foi o sorriso, sendo relatado por uma mãe e dois pais, na primeira etapa, e três mães e quatro pais na segunda.

Quando foram perguntados se seus filhos podiam sentir raiva, 16 mães e 14 pais na $1^{a}$ etapa responderam que "sim", e igual resposta foi apresentada por 19 mães e 18 pais na $2^{\mathrm{a}}$ etapa. Aos 3 meses, segundo os relatos, os bebês expressavam raiva principalmente por meio do choro, mencionado por nove mães e quatro pais, como no exemplo: "Raiva de vez em quando e quando chora, chora grosso." (P8). Vocalizações também foram indicadas como um comportamento frequente para expressar raiva na $1^{a}$ etapa, o exemplo abaixo remete ao que foi mencionado por cinco mães e um pai: "Quando tá com raiva? falando, né, reclamando, balbuciando." (M17). $\mathrm{Na} 2^{\mathrm{a}}$ etapa, a ordem dos comportamentos foi inversa, a emissão de sons, tipo vocalizações, foi referida por sete mães e nove pais, e o choro por seis mães e oito pais.

Sobre tristeza, 14 mães e 17 pais na $1^{a}$ etapa, e 12 mães e 14 pais na $2^{a}$ etapa relataram que percebem que seus filhos a expressam, particularmente, por meio do choro. A respeito da concepção parental sobre a capacidade de seus filhos sentirem culpa, a maioria acredita que tanto aos 3 meses (19 mães e 18 pais) quanto aos 6 meses (17 mães e 19 pais), os bebês ainda não podem ter tal sentimento: "Acho que ele não sente não, tá fora de condições." (P10, 6 meses).

\section{Concepsões Parentais acerca da Percepção do bebê de Comunicar e Satisfazer suas Próprias Necessidades}

A quase totalidade dos participantes, nos dois períodos de desenvolvimento dos seus filhos, afirmou perceber o choro do bebê como um comportamento que busca comunicar algo. Quando os bebês estavam com 3 meses, a maioria dos participantes (20 mães e 19 pais) mencionou que o choro era utilizado pelo bebê para expressar necessidades ou incômodo, como demonstrado no exemplo: "Com certeza, uma forma de manifestar uma necessidade que ele tem (...). O estado normal dele não é chorar, né. Então, quando ele chora, ele quer demonstrar, do jeitinho dele que não fala ainda, que alguma coisa tá incomodando." (M20).

$\mathrm{Na} 2^{\mathrm{a}}$ etapa, além de mencionarem as necessidades infantis, seis mães e cinco pais relataram que o choro é frequentemente usado pelos bebês para expressar vontades, o que para os participantes parecia estar associado à "manha" demonstrada por seus filhos nessa etapa do desenvolvimento. O recorte de fala a seguir ilustra essa ideia: "Muitas vezes é manha, certo. Ela chora por manha. Ela chora por fome. Ela chora com sono. Eu acho que esses três são os principais." (M18).

Também, nessa seção, os pais foram questionados sobre o interesse que seus filhos têm pelos objetos e quais comportamentos usam para expressá-lo. A maioria dos pais e mães afirmou que seus filhos demonstram interesse por objetos. $\mathrm{Na} 1^{\mathrm{a}}$ etapa da pesquisa, o principal comportamento elencado foi tentar e/ou pegar o objeto, referido por 16 mães e 14 pais, como no exemplo: "Ela demonstra interesse (...). Ela sempre quer pegar. Ela fica afoita, se mexendo muito, as perninhas, os bracinhos. Ela tenta pegar, mas não tem força, né." (M2, 3 meses). Em seguida, foi mencionado, por sete mães e seis pais, o olhar.

$\mathrm{Na} 2^{\mathrm{a}}$ etapa, o olhar foi mencionado com menor frequência e prevaleceu a habilidade infantil de pegar os objetos que despertam seu interesse, relatada por 17 mães e 16 pais: "Pegando [...]. Quando ela quer pegar, ela vai e pega mesmo, mete mesmo." (M6). Nessa etapa, os relatos estavam focados em "pegar o objeto", e não mais em tentar pegar.

\section{Concepcôees Parentais acerca da Percepção do Bebê sobre os Es- tados dos Outros}

Foi perguntado se os pais achavam que os bebês podem perceber o humor parental, a maioria respondeu de modo afirmativo. Na $1^{\text {a }}$ etapa, 16 mães e 17 pais responderam que seus filhos são capazes de perceber $\mathrm{o}$ humor dos seus cuidadores e que existem variações nos comportamentos infantis dependendo do humor que eles percebem. O mesmo foi apresentado nas respostas de 17 mães e 14 pais, na $2^{a}$ etapa. Uma mãe e dois pais, nas duas etapas da pesquisa acreditavam que os bebês são capazes de perceber as suas modificações de humor, todavia, alegaram que isso não acarreta modificações no comportamento infantil.

Concepções Parentais acerca da Percepção dos Bebês sobre a Eficácia dos seus Comportamentos nas Interações com Outros

Questionados sobre o sorriso do bebê, a maioria dos pais e mães, nas duas etapas do desenvolvimento dos bebês, respondeu que percebe o sorriso do bebê como indicativo de felicidade e de resposta aos pais, como demonstrado no exemplo: "Eu acho que ela, por exemplo, quer continuar, por exemplo, a brincadeira, né." (M1, 3 meses).

Também nessa seção os pais descreveram a interação dos seus filhos com outras crianças. $\mathrm{Na} 1^{\text {a }}$ 
etapa, 16 mães e 15 pais responderam que seus bebês interagem bem com crianças. De acordo com os relatos, os principais comportamentos dos bebês ao ver outra criança são sorrir, mencionado por nove mães e sete pais, e olhar, comentado por oito mães e seis pais. $\mathrm{Na} 2^{\mathrm{a}}$ etapa, praticamente todos os participantes afirmaram que seus filhos interagem bem com outras crianças, mas, nessa etapa, o principal comportamento infantil é tentar pegar, mencionado por 10 mães e 11 pais: "Quando coloca uma criança perto dele, ele quer pegar, ele quer tá tocando." (P20). Em seguida foram referidos o olhar, por oito mães e oito pais, e o sorriso, por cinco mães e 11 pais.

A pergunta seguinte foi "Você acha que o seu bebê, em algum momento, se comporta com a intenção de modificar o seu comportamento?". Na $1^{\text {a }}$ etapa, oito mães e sete pais responderam afirmativamente e citaram como principais comportamentos direcionados para esse fim o choro e a emissão de sons. $\mathrm{Na} 2^{\mathrm{a}}$ etapa, o número de participantes que responderam "sim" aumentou, foram 16 mães e 12 pais e, como principais comportamentos, foram elencados o choro e "fazer birra", como no exemplo: "Sim. Quando ele quer sair do berço que eu digo para ele ficar, ele faz birra pra sair. Não quer ficar no carrinho. Essas coisas.” (M13).

A última questão dessa seção foi referente às concepções parentais acerca da capacidade infantil de comportar-se negativamente de propósito. $\mathrm{Na} 1^{a}$ etapa da pesquisa, cinco mães e oito pais responderam "sim". Enquanto que, na $2^{\mathrm{a}}$ etapa, essa resposta afirmativa foi apontada por 10 mães e 10 pais, que correspondem à metade dos participantes do estudo.

\section{Discussão}

A análise dos dados permitiu identificar as semelhanças e diferenças nos relatos parentais acerca da habilidade de comunicação intencional infantil nas duas etapas do estudo, ou seja, aos 3 e 6 meses dos bebês. Verificou-se que os relatos maternos e paternos referiram o mesmo tipo de concepção, não apresentando diferenças muito expressivas, exceto em alguns aspectos particulares. As principais diferenças estão relacionadas ao período de desenvolvimento do bebê. Dito de outra forma, os relatos de pais e mães são mais semelhantes entre si do que quando comparados os relatos da $1^{\mathrm{a}}$ e da $2^{\mathrm{a}}$ etapa. A partir dos discursos parentais, foram elencados os principais comportamentos infantis considerados pelos pais como comportamentos comunicativos, por vezes indicadores de intenção, os principais foram: choro, sorriso, expressões faciais, expressões de carinho e "pegar".

O choro foi o comportamento infantil mais presente nos discursos dos participantes, sendo apresentado em três momentos distintos da entrevista como o principal comportamento do bebê para: expressar emoções negativas (medo, raiva e tristeza); comunicar e ter suas necessidades e/ou vontades satisfeitas; e mudar, intencionalmente, o comportamento dos outros. Esse comportamento, como um meio de demonstrar emoções, emergiu de forma mais marcante no discurso de mães e pais de bebês aos 3 meses, ao responderem como seus filhos expressam medo e raiva. Sobre raiva, o número de pais e mães que acham que seu bebê pode ter esse sentimento aumentou ao passar do tempo. Além da frequência, as concepções parentais sobre os comportamentos infantis usados para expressar raiva também foram diferentes nos dois momentos do desenvolvimento.

Enquanto que, aos 3 meses, os relatos sobre o choro foram predominantes, aos 6 meses, apesar de o choro ainda se manter presente, as vocalizações foram mencionadas. Essa diferença está diretamente relacionada às modificações ao longo do desenvolvimento infantil. Aos 6 meses, os bebês dispõem de uma diversidade maior de habilidades que são percebidas pelos pais como novas formas de expressão.

Com relação à tristeza, esse foi o único sentimento cujos pais relataram com mais frequência do que as mães que seus bebês podiam expressá-lo. Esse dado levanta algumas questões, especificamente sobre as concepções paternas: será que os pais percebem mais a tristeza do que as mães? Ou, tendo as mães, em geral, mais habilidade para interpretar corretamente o choro infantil, elas atribuem a esse comportamento outros motivos, enquanto que os pais remetem o choro à tristeza?

$\mathrm{Na}$ tentativa de responder a essas questões, foram retomados, além dos dados referentes às concepções parentais, os dados sociodemográficos dos participantes. Nesse sentido, constatou-se que os pais passavam menos tempo com seus filhos do que as mães, e esse é um dos aspectos que pode tornar o pai menos envolvido nos cuidados infantis. Esse fator parece contribuir para a dificuldade paterna em diferenciar o choro do bebê, fazendo com que o pai, mais frequentemente, atribua o choro ao sentimento de tristeza, algumas vezes justificada como "tristeza do bebê por estar longe da mãe".

Esse dado corrobora estudos na área, como o de Castoldi et al. (2014) que constatou que os pais têm mais dificuldades em se envolver nos cuidados infantis 
quando os bebês estão chorando. Em outra pesquisa realizada por Piccinini, Silva, Gonçalves, Lopes e Tudge (2012), também com pais, a maioria dos participantes expressou dificuldades e/ou um sentimento de incompetência ao realizar algumas atividades com o bebê, com destaque para a dificuldade em acalmar o bebê enquanto ele chorava.

Outra concepção indicada pelos participantes do presente estudo foi que os bebês usam o choro para comunicar e ter suas necessidades e/ou vontades satisfeitas. $\mathrm{Na} 1^{a}$ etapa, os pais falaram desse comportamento como sendo exclusivamente uma forma de comunicar necessidades e incômodo. $\mathrm{Na} 2^{\mathrm{a}}$ etapa, os discursos destacaram o choro do bebê como dotado de intenção, podendo também ser uma expressão de vontades. Essa diferença nos relatos das duas etapas aponta a ideia de que o choro, a partir de determinado período, começa a ser entendido pelo bebê como tendo uma função comunicativa e passa a ser usado com indícios de intencionalidade, tal como apontado pela literatura na área (Barr, 2011; Papalia \& Feldman, 2013).

Barr (2011) e Papalia e Feldman (2013) afirmam que, até aproximadamente o final do primeiro semestre de vida, o choro do bebê ainda não é apresentado como uma forma deliberada de comunicação. Em torno dos 5 meses de idade é que o choro começa a torna-se mais contextualizado e a ser usado de modo reativo, tanto para expressar os incômodos e vontades do bebê, quanto para responder a fatores das interações ou do ambiente. Essas modificações nos significados do choro, além de transformarem o comportamento infantil, têm implicações no modo como os cuidadores interpretam e agem frente ao choro do bebê. Nesse sentido, Nunes e Braz Aquino (2014), também verificaram que os relatos de mães de bebês mais velhos evidenciaram que eles conseguem usar o choro com outros objetivos que, ao longo do processo de desenvolvimento, vão adquirindo o caráter intencional, permitindo que o bebê aumente seu efeito no meio social. Melchiori e Alves (2004), em um estudo realizado com educadoras infantis, constataram que elas percebem que os bebês, com o aumento da idade, choram menos e, quando o fazem, expressam necessidades diversas, além das necessidades primárias.

O terceiro momento da entrevista no qual os participantes mencionaram o choro foi ao serem questionados sobre a capacidade infantil de se comportar com a intenção de mudar o comportamento do outro. Sobre isso, as respostas diferiram conforme a idade dos bebês. O número de relatos parentais que consideram que seus filhos podem se comportar com a intenção de mudar o comportamento dos cuidadores quase dobrou, quando comparado os relatos aos $3 \mathrm{e}$ aos 6 meses. Esses dados trazem implicações para as práticas parentais, tendo em vista que, ao perceberem que os bebês se comportam com uma determinada intenção, os pais tendem a buscar identificar o que realmente o bebê quer comunicar, ao invés de atribuírem um sentido rapidamente. Esse tipo de ação parental permite que eles atendam às solicitações do bebê de forma mais precisa, alterando positivamente as interações diádicas.

Outro comportamento levantado neste estudo se refere ao sorriso, indicado pelos participantes como o principal meio pelo qual os bebês expressam felicidade e também como uma importante forma de expressar amor, sendo relacionado, pelos participantes, às emoções positivas. Esse comportamento também foi mencionado, predominantemente pelos pais, como um dos principais usados pelos bebês na interação com outras crianças. Além disso, nas duas etapas, a maioria dos pais e mães afirmou que o sorriso infantil é um dos principais comportamentos comunicativos utilizados para intervir no comportamento do outro. Esse dado indica que os pais percebem o sorriso do bebê como um sinal social que facilita a relação com seus pares e a proximidade com os cuidadores, sendo utilizado para dar continuidade às interações, corroborando estudos na área (Mendes \& Seidl de Moura, 2009; Souza et al., 2014).

Resultados semelhantes foram encontrados por Braz Aquino e Salomão (2011), ao estudarem interações mãe-bebê aos 6 meses, e por Krob, Piccinini e Silva (2009), em uma pesquisa sobre a relação pai-filho. As primeiras autoras citadas identificaram o sorriso como um sinalizador para as mães continuarem uma atividade específica ou inferirem que o bebê estaria interessado no evento ou objeto, como indicado no presente estudo.

Ao falarem sobre as emoções que os bebês são capazes de sentir, os pais também relataram as expressões faciais de modo geral, por entenderem que elas são uma forma de linguagem corporal, que se manifesta, particularmente, na ausência da fala e comunicam sentimentos e estados infantis. Destaca-se que os relatos que mencionaram as expressões faciais relacionavam-nas à surpresa, especialmente na $2^{\mathrm{a}}$ etapa do estudo. Verificou-se que os participantes entendem que as expressões faciais representam um importante sinal social, organizado de modo flexível em configurações que transmitem mensagens sobre o estado interior e as 
intenções de bebês, sendo eficaz para iniciar interações sociais. Esses resultados corroboram dados apresentados por Mendes e Pessôa (2013) que, ao discutirem as expressões afetivas nas interações mãe-bebê, esclarecem que as expressões faciais são pistas dadas pelos bebês ao adulto sobre suas emoções. Destaca-se, então, conforme afirmado por Mendes e Seidl de Moura (2009), a importância das expressões faciais da emoção para a compreensão do desenvolvimento cognitivo, afetivo e social.

Ainda sobre as expressões faciais, os participantes relataram que os bebês também são capazes de reconhecê-las em seus cuidadores, identificando, por meio delas, o humor destes. A maioria dos pais e mães percebeu que as variações no humor deles são reconhecidas pelos bebês, que, por sua vez, podem modificar seus comportamentos em função disso. Sobre essa temática, autoras (Legerstee, 2013; Mendes \& Pessôa, 2013) esclarecem que, ao longo do desenvolvimento infantil, os bebês começam a criar expectativas em relação ao adulto e a reagir a seus comportamentos e expressões faciais. Assim, conforme dados do presente estudo e da literatura, as emoções dos cuidadores podem ter efeitos sobre os bebês, particularmente efeitos negativos quando os pais expressam sentimentos de tristeza ou estresse.

Essa ideia dos pais é refletida nos seus discursos sobre as práticas. Os participantes mencionaram que por considerarem que os seus filhos são capazes de distinguir quando eles estão felizes ou não, os pais se esforçam para manter as interações com os bebês de forma agradável, ainda que isso signifique tentar esconder seus problemas ou humores negativos. Verificou-se, nesses relatos, a preocupação dos participantes em transmitir afetos positivos para os bebês, por acreditarem que isso tem implicações no desenvolvimento infantil saudável.

Outra forma que, segundo os relatos parentais, é usada pelos bebês para expressar emoções é a demonstração de carinho. Tal comportamento foi relatado nas respostas dos participantes sobre a expressão infantil de amor, e foram verificadas diferenças nos relatos conforme a idade dos bebês. Constatou-se que as falas dos pais, na $2^{a}$ etapa, demonstravam formas mais elaboradas de manifestações de carinho. Isso parece refletir as concepções parentais acerca de um bebê mais ativo nesse período. Entende-se que essas ações mais sofisticadas são influenciadas diretamente pelas novas aquisições motoras, que provocam importantes mudanças nos comportamentos e nas experiências dos bebês. Os avanços motores também estão relacionados aos discursos parentais que relataram o "pegar" como um comportamento comunicativo infantil. Esse tipo de resposta foi referido pelos pais ao falarem sobre a habilidade dos seus filhos em demonstrarem interesse pelos objetos e a interação deles com outras crianças. $\mathrm{Na} 1^{\mathrm{a}}$ etapa, nos relatos parentais predominou o ato de tentar pegar o objeto; e, na $2^{\text {a }}$ etapa, o ato de pegar o objeto foi o mais mencionado. Com relação à interação entre pares, o "pegar" foi relatado apenas aos 6 meses.

Esses dados apontam indícios da comunicação intencional e de movimentos que sugerem que a sensibilidade para a atenção triádica é funcional, corroborando ideias apresentadas por Striano e Reid (2006) e Rochat (2009). Ademais, retratam a interdependência entre os diversos domínios do desenvolvimento, como os avanços motores, que podem influenciar diretamente e potencializar novas habilidades comunicativas.

Tais avanços intensificam o comportamento exploratório e interativo do bebê com os outros e com o meio ambiente ao longo do primeiro ano de vida. Quando isso é percebido pelos pais, espera-se que eles respondam ativamente a esses sinais, seja por meio de palavras ou ações e, assim, beneficiem o aprendizado infantil sobre os objetos e o contexto no o bebê qual está inserido (Tamis-LeMonda, Kuchirko, \& Song, 2014).

Outro tema presente nos relatos que merece destaque é a concepção parental acerca da capacidade infantil de comporta-se negativamente de propósito. Respostas afirmativas foram mais frequentes quando os bebês estavam com 6 meses. Todavia as respostas aos 3 meses, embora em menor frequência, também mostraram-se relevantes, indicando que alguns pais já percebiam comportamentos infantis específicos (ex.: chutar durante a troca de fraldas) como sendo comportamentos negativos com indícios de intencionalidade. Participantes, na $2^{\mathrm{a}}$ etapa, indicaram, como um comportamento negativo do bebê, "fazer birra" com a intenção de mudar os comportamentos parentais e ter suas vontades atendidas. Esse tipo de concepção parental pode ser associado a práticas relacionadas à disciplina e, considerando que os pais concebem que os bebês podem agir negativamente de propósito, então, eles tendem a não incentivar ou punir esse tipo de comportamento. Os dados apresentados ratificam um estudo realizado por Burchinal et al. (2010) que indicou que mães de bebês de 6 meses apresentaram relatos sobre a necessidade de ensinar regras sociais aos bebês.

De modo geral, depreende-se que as concepções parentais apresentadas sobre a comunicação 
intencional infantil evidenciam que o bebê, ao desenvolver a habilidade de perceber que suas ações têm efeitos nos comportamentos dos seus cuidadores, avança para formas de comunicação mais sofisticadas e, progressivamente, mais intencionais. Inicialmente, ele é guiado pelos interesses dos outros em relação ao contexto, mas, ao longo do processo de desenvolvimento, começa a explorar meios de chamar atenção para si e para os seus comportamentos e vontades. Essas ações infantis, por seu turno, influenciam o modo como os pais percebem e, direta ou indiretamente, agem com o bebê, caracterizando uma relação bidirecional.

Ademais, pontua-se que os comportamentos emitidos pelos bebês, bem como o modo que as mães e os pais os veem e interpretam, estão diretamente relacionados às características culturais típicas desse grupo de participantes. Diferenças nesses aspectos podem resultar em variações relativas às práticas de criação.

\section{Considerações Finais}

O objetivo do presente estudo foi conhecer e analisar as concepções parentais acerca do desenvolvimento da intencionalidade comunicativa aos 3 e aos 6 meses do primeiro ano de vida dos bebês. De acordo com os resultados, verificou-se que os pais percebem comportamentos infantis que podem ser indícios da habilidade de comunicação intencional. Embora as ações dos bebês ainda não sejam marcadas por comportamentos convencionalmente entendidos como intencionais, nota-se que o choro, o sorriso e "fazer birra" são entendidos, especialmente aos 6 meses, como comportamentos que expressam vontades e indicam intenções. De modo geral, tais comportamentos iniciais são utilizados com maior frequência antes do desenvolvimento verbal e, ao longo do tempo, tornam-se mais elaborados e direcionados para um objetivo.

Considera-se que essa pesquisa apresenta contribuições relevantes, particularmente, ao estudo das concepções paternas sobre o desenvolvimento infantil. Foi possível identificar o que os pais pensam sobre algumas áreas do desenvolvimento dos seus filhos e esses dados podem fornecer pistas sobre as práticas paternas de cuidado. Nesse sentido, o presente estudo identificou mais semelhanças do que diferenças entre os discursos maternos e paternos, desmistificando a ideia de que o pai parece não conhecer o desenvolvimento do bebê. Os resultados podem contribuir para fundamentar práticas profissionais nas áreas de saúde e educação, que objetivem promover o desenvolvimento infantil por meio de ações voltadas para cuidadores primários, como as mães e os pais.

Apesar disso, pontua-se que os dados, além de serem referentes a um número limitado de participantes, remetem às concepções de um grupo diferenciado de outros extratos da sociedade por apresentarem algumas características sociodemográficas, tal como ter nível instrucional elevado, acima da média nacional. Portanto, os resultados devem ser considerados de modo cauteloso, considerando suas particularidades. Outra limitação do presente estudo é que os dados foram coletados em apenas dois momentos do desenvolvimento inicial. Sugere-se que futuras pesquisas abarquem outros períodos do desenvolvimento infantil, especialmente o final do primeiro ano de vida do bebê, e atentem para o papel das concepções de outros cuidadores infantis.

\section{Referências}

Bardin, L. (2002). Análise de Conteúdo. Lisboa/Portugal: Edições 70.

Barr, R. G. (2011). O choro e sua importância para o desenvolvimento psicossocial da criança. Enciclopédia sobre o Desenvolvimento na Primeira Infância. Canadá: Centre of Excellence for Early Childhood Development.

Braz Aquino, F. S., \& Salomão, N. M. R. (2010). Intencionalidade comunicativa: Teorias e implicações para a cognição social infantil. Estudos de Psicologia (Campinas). 27(3), 413-420.

Braz Aquino, F. S. \& Salomão, N. M. R. (2011). Percepções maternas acerca das habilidades sociocomunicativas de bebês. Psicologia: Ciência e Profissão. 31(2), 252-267.

Bueno, R. K., \& Vieira, M. L. (2014). Análise de estudos brasileiros sobre o pai e o desenvolvimento infantil. Psicologia Argumento, 32(76), 151-159.

Burchinal, M., Skinner, D., \& Reznick, J. S. (2010). European American and African American mothers' beliefs about parenting and disciplining infants: A mixed-method analysis. Parenting: Science And Practice, 10, 79-96.

Carpenter, M. (2011). Social cognition and social motivations in infancy. Em U. Goswami (Ed.). The Wiley-blackwell Handbook of Childhood Cognitive Development (pp. 106-128). Blackwell publishing.

Psico-USF, Bragança Paulista, v. 23, n. 1, p. 71-82, jan./mar. 2018 
Castoldi, L., Gonçalves, T. R., \& Lopes, R. C. S. (2014). Envolvimento paterno da gestação ao primeiro ano de vida do bebê. Psicologia em Estudo, 19(2), 247-259, Maringá.

Dessen, M. A., \& Oliveira, M. R. (2013). Envolvimento paterno durante o nascimento dos filhos: Pai "real" e "ideal" na perspectiva materna. Psicologia: Reflexão e Crítica, 26(1), 184-192.

Dunbar, R. I. M. (2013). An evolutionary basis for social cognition. Em M. Legerstee, D. Haley \& M. H. Bornstein (Eds.), The Infant Mind: Origins of the Social Brain. (pp. 3-18). New York, NY: Guilford Press.

Feldman, R., \& Reznick, J. S. (1996). Maternal perception of infant intentionality at 4 and 8 months. Infant Behavioral Development, 19, 483-496.

Frye, D. (2014). The origins of intention in infancy. Em D. Frye \& C. Moore (Eds.), Children's Theories of Mind: Mental States and Social Understanding. (pp. 1538). New York, NY: Psychology Press.

Grosse, G., Behne, T., Carpenter, M., \& Tomasello, M. (2010). Infants communicate in order to be understood. Developmental Psychology, 46(6), 1710-1722.

Krob, A. D., Piccinini, C. A., \& Silva, M. R. (2009) A transição para a paternidade: Da gestação ao segundo mês de vida do bebê. Psicologia USP, 20(2), 269-291.

Legerstee, M. (2013). The developing social brain: Social connections and social bonds, social loss, and jealousy in infancy. Em M. Legerstee, D. Haley, \& M. H. Bornstein (Eds.), The Infant Mind: Origins of the Social Brain. (pp. 223-247). New York, NY: Guilford Press.

Melchiori, L. E., \& Alves, Z. M. M. B. (2004) Estratégias que educadoras de creche afirmam utilizar para lidar com o choro dos bebês. Interação em Psicologia, 8(1), 45-43.

Mendes, D. M. L. F., \& Pessôa, L. F. (2013). Emotion, affection and maternal speech in parental care. Em M. L. Seidl de Moura (Ed.), Parenting in South American and African Contexts. (pp. 130-145). InTech. Recuperado de http://creativecommons.org/ licenses/by/3.0

Mendes, D. M. L. F., \& Seidl de Moura, M. L. (2009). Expressões faciais de emoção em bebês: Importância e evidências. Estudos em psicologia. 9(2), 307-327.
Nunes, L. de L., \& Braz-Aquino, F. de S. (2014). Habilidade de comunicação intencional de bebês: $\mathrm{O}$ que pensam as mães? Psicologia: Teoria e Pesquisa. 30(4), 363-372.

Papalia, D. E., \& Feldman, R. D. (2013). Desenvolvimento bumano. 12 ed. Porto Alegre, Mc Graw Hill - Artmed.

Piccinini, C. A., Silva, M. R., Gonçalves, T. R., Lopes, R. C. S., \& Tudge, J. (2012). Envolvimento paterno aos três meses de vida do bebê. Psicologia: Teoria e Pesquisa, 28(3), 303-314.

Rivero, M. (2003). Lós inícios de La comunicación: La intencionalidad comunicativa y el significado como procesos graduales. Anuário de Psicologia, 34(3), 337-356.

Rochat, P. (2007). Intentional action arises from early reciprocal exchanges. Acta Psychologica, 124, 8-25.

Rochat, P. (2009). Others in mind: Social origins of self-consciousness. New York, NY: Cambrige Univerty Press.

Rochat, P. (2015). Self-conscious roots of human normativity. Phenom Cogn Sci. doi 10.1007/ s11097-015-9427-x

Sanchez, S. E. (1991). Observacion de la comunicacion intencional preverbal: Um sistema de codificacion basado en el concepto de categoria natural. Psicothema, 3(2), 359-380.

Seabra, K. C., \& Seidl de Moura, M. L. (2011). Cuidados paternos nos primeiros três anos de vida de seus filhos: Um estudo longitudinal. Interaşão Psicologia, 15(2), 135-147.

Souza, C. G., Machado, G. M. A., Nunes, L. L., \& Braz Aquino, F. S. (2014). Crenças maternas sobre o desenvolvimento sociocomunicativo de bebês. Temas em Psicologia, 22(2), 483-495.

Striano, T. \& Reid, V. M. (2006) Social cognition in the first year. TRENDS in Cognitive Sciences, 10(10), 471-476.

Striano. T. \& Rochat. P.(1999). Developmental link between dyadic and triadic social competence in infancy. British Journal of Developmental Psychology, 17, 551-562.

Striano, T. \& Stahl, D. (2005). Sensitivity to triadic attention in early infancy. Developmental Science, 8(4), 333-343. 
Tamis-LeMonda, C. S., Kuchirko, Y., \& Song, L. (2014). Why is infant language learning facilitated by parental responsiveness? Current Directions in Psychological Science, 23(2) 121-126.

Tomasello, M. (2003). Origens culturais da aquisição do conhecimento bumano: Tópicos (C. Berliner, Trad.). São Paulo, SP: Martins Fontes.

Trevarthen, C., \& Delafield-Butt, J. (2013). Biology of shared experience and language development: Regulations for the intersubjective life of narratives. Em M. Legerstee, D. Haley \& M. H. Bornstein
(Eds.), The Infant Mind: Origins of the Social Brain. (pp. 167-199). New York, NY: Guilford Press.

Vieira, M. L., Bossardi, C. N., Gomes, L. B., Bolze, S. D. A., Crepaldi, M. A., \& Piccinini, C. A. (2014). Paternidade no Brasil: Revisão sistemática de artigos empíricos. Arquivos Brasileiros de Psicologia, 66(2), 36-52.

Recebido em: 24-05-2016

Reformulado em: 17-07-2016; 03-08-2016

Aprovado em: 29-08-2016

Nota das autoras:

Apoio: CAPES

Sobre as autoras:

Laísy de Lima Nunes é graduada e licenciada em Psicologia pela Universidade Estadual da Paraíba (2011), mestre em Psicologia Social pelo Programa de Pós-Graduação em Psicologia Social da Universidade Federal da Paraíba, doutoranda em Psicologia Social pelo PPGPS/UFPB e membro do Núcleo de Estudos em Interação Social e Desenvolvimento Infantil (NEISDI/UFPB).

E-mail: laisynunes@gmail.com

Fabíola de Sousa Braz Aquino é psicóloga pela Universidade Federal da Paraíba (1997), mestre e doutora em Psicologia Social (UFPB), professora do Departamento de Psicologia e do Programa de Pós-Graduação em Psicologia Social da Universidade Federal da Paraíba, pesquisadora do NEISDI/UFPB, membro do GT de Psicologia Escolar Educacional da ANPEPP e realiza pesquisas em Psicologia do Desenvolvimento infantil, Psicologia Escolar Educacional e Educação Infantil.

E-mail: fabiolabrazaquino@gmail.com

Nádia Maria Ribeiro Salomão é psicóloga pela Universidade de São Paulo (1978), mestre em Educação Especial (UFSCar), doutora em Psicologia (University of Manchester), pós-doutora pela University of North Carolina, professora do Departamento de Psicologia e do Programa de Pós-Graduação em Psicologia Social da Universidade Federal da Paraíba, pesquisadora do NEISDI/UFPB e membro do GT de Parentalidade e desenvolvimento infantil em diferentes contextos da ANPEPP.

E-mail:nmrs@uol.com.br

Contato com as autoras:

Rua Capitão Severino Cesarino da Nóbrega, 210, apto 203

Jardim São Paulo

João Pessoa-PB, Brasil

CEP: 58051-220 